\title{
Lipid Metabolism Profiles in Rheumatic Diseases
}

\author{
Weilin Chen ${ }^{1,2,3}$, Qi Wang ${ }^{4}$, Bin Zhou ${ }^{5}$, Lihua Zhang ${ }^{6}$ and Honglin Zhu ${ }^{1,2,3 *}$ \\ ${ }^{1}$ Department of Rheumatology, Xiangya Hospital, Central South University, Changsha, China, ${ }^{2}$ National Clinical \\ Research Center for Geriatric Disorders, Xiangya Hospital, Changsha, China, ${ }^{3}$ Provincial Clinical Research Center for \\ Rheumatic and Immunologic Diseases, Xiangya Hospital, Changsha, China, ${ }^{4}$ Department of Radiology, Hunan \\ Provincial People's Hospital, The First Affiliated Hospital of Hunan Normal University, Changsha, China, ${ }^{5}$ Department \\ of Nephrology, The Affiliated Hospital of Qingdao University, Qingdao, China, ${ }^{6}$ Department of Rheumatology, Hunan \\ Provincial People's Hospital, The First Affiliated Hospital of Hunan Normal University, Changsha, China
}

Rheumatic diseases are a group of chronic autoimmune disorders that involve multiple organs or systems and have high mortality. The mechanisms of these diseases are still illdefined, and targeted therapeutic strategies are still challenging for physicians. Recent research indicates that cell metabolism plays important roles in the pathogenesis of rheumatic diseases. In this review, we mainly focus on lipid metabolism profiles (dyslipidaemia, fatty acid metabolism) and mechanisms in rheumatic diseases and discuss potential clinical applications based on lipid metabolism profiles.

\section{OPEN ACCESS}

Edited by:

Jian Gao,

Second Affiliated Hospital of Dalian Medical University, China

Reviewed by: Hai-Feng Pan, Anhui Medical University, China Sheng Wang, Fifth People's Hospital of Suzhou, China

*Correspondence: Honglin Zhu HonglinZhu@csu.edu.cn

Specialty section: This article was submitted to Inflammation Pharmacology, a section of the journal

Frontiers in Pharmacology

Received: 18 December 2020

Accepted: 18 February 2021

Published: 09 April 2021

Citation:

Chen W, Wang Q, Zhou B, Zhang L and Zhu H (2021) Lipid Metabolism

Profiles in Rheumatic Diseases.

Front. Pharmacol. 12:643520.

doi: 10.3389/fphar.2021.643520
Keywords: dyslipidemia, fatty acid metabolism, rheumatic diseases, lipid metablism, statin

\section{INTRODUCTION}

Rheumatic diseases are a group of chronic heterogeneous autoimmune disorders that involve multiple organs or systems and cause high mortality and disability. The major rheumatic diseases include systemic lupus erythematous (SLE), rheumatoid arthritis (RA), systemic sclerosis (SSc), idiopathic inflammatory myopathy (IIM), and Sjögren's syndrome (pSS). The pathogenesis of rheumatic diseases is complicated and poorly defined.

Recently, immunometabolism has been widely studied in autoimmune and rheumatic diseases, and studies have mainly focused on six major metabolic pathways, including glycolysis, the tricarboxylic acid (TCA) cycle, the pentose phosphate pathway (PPP), amino acid metabolism, fatty acid (FA) oxidation and FA synthesis. Among these pathways, research into lipid metabolism has been ongoing for years (Rhoads et al., 2017; Peradze et al., 2019). For example, dyslipidaemia was associated with $\mathrm{CD} 4^{+} \mathrm{T}$ cell activation and complement-mediated renal damage in lupus-prone mouse models (Woo et al., 2010; Black et al., 2015). Statin suppressed the secretion of pro-inflammatory cytokines by macrophages and T cells in RA patients (Kwak et al., 2000). In SSc and fibrotic disease, lipid metabolism was a key mediator in the activation of fibroblasts and immune cells. In addition, adipose tissue is correlated with oxidative stress and participates in vascular damage (Winsz-Szczotka et al., 2016).

Dyslipidaemia is characterized by lower high-density lipoprotein (HDL) levels and higher low-density lipoprotein (LDL), triglyceride (TG), and total cholesterol (TC) levels, and it is commonly found in rheumatic diseases. It is well known that high levels of LDL and/or abnormal levels of HDL in the plasma are strongly correlated with an increased risk of atherosclerosis (Expert, 2001) and end-organ damage, such as central nervous system and kidney damage 
(Tselios et al., 2016). Here, we summarize the profiles of lipid metabolism in rheumatic diseases and explore potential clinical applications.

\section{LIPID METABOLISM DISORDERS IN SLE}

SLE is a chronic autoimmune disease that involves multiple organs and is characterized by heterogeneous symptoms (Kaul et al., 2016). A high risk of dyslipidaemia is observed in SLE patients. Hypercholesterinaemia was observed in 36\% of newly diagnosed SLE patients from the International Collaborating Clinics cohort, with even higher levels after being diagnosed for 3 years (Urowitz et al., 2007). Dyslipidaemia can affect the prognosis of SLE patients through both cardiovascular disease (CVD)-related events and damage to other organs, such as lupus nephritis (Tselios et al., 2016).

\section{Dyslipidaemia in SLE High-Density Lipoprotein}

Pro-inflammatory HDL (piHDL) was found in $44.7 \%$ of female SLE patients and $20.1 \%$ of female RA patients but in only $4.1 \%$ of healthy women (McMahon et al., 2006). Dysfunctional piHDL notably increased the prevalence of subclinical atherosclerosis and carotid plaque, with higher intima-media thickness (IMT), in SLE patients (Wu et al., 2016), especially in female patients (McMahon et al., 2014). In addition, the occurrence of ischaemic heart disease is 50-fold higher in female SLE patients of childbearing age (Manzi et al., 1997; Manzi et al., 1999). Decreased HDL and Apo A-1 and increased oxidized LDL (ox-LDL) auto-antibody levels were also observed in paediatric SLE patients (Soep et al., 2004; Yuan et al., 2016). Paraoxonase-I (PON-1) is a subfraction of HDL (Durrington et al., 2001), which can protect LDL from oxidation (Mackness et al., 1991). PON-1 might inhibit the synthesis of cholesterol in macrophages and promote HDL reverse cholesterol transport (Aviram and Rosenblat, 2004). The levels of plasma PON-1 are decreased in SLE patients (Kiss et al., 2007), and reduced PON-1 activity may be involved in SLE complications.

It has been widely recognized that HDLs are involved in the anti-inflammatory processes (Saemann et al., 2010). The mechanisms of the anti-inflammatory effects are still elusive. HDL can activate the transcriptional repressor activating transcription factor 3 (ATF-3) thus inhibits Toll-like receptor (TLR) pathways and TLR-induced cytokines (De Nardo et al., 2014). HDL can also inhibit NF- $\kappa B$ mediated vascular inflammation (Park et al., 2003). Compared to control HDL, SLE HDL can activates NF- $\kappa \mathrm{B}$, increase the production of inflammatory cytokine production, decrease ATF3 synthesis and activity in a LOX1R- and ROCK1/2-dependent manner. HDL-targeted therapies can serve as potential therapeutic intervention for SLE patients with CVD (Smith et al., 2017; Kim et al., 2020).

\section{Low-Density Lipoprotein}

LDL becomes oxidized in the vascular wall and induces monocyte chemotaxis in SLE patients (Hansson, 2005; Narshi et al., 2011).
Normal HDL can protect LDL from oxidation in vivo (Navab et al., 2004), thus decreasing the risk of CVD in SLE patients (Gaal et al., 2016). Increased LDL and/or ox-LDL levels are positively correlated with plaque inflammation in SLE patients, especially in female patients. Adaptive immune responses might diminish inflammation and accelerate vascular repair (Wigren et al., 2015). Nevertheless, long-term exposure to high levels of LDL will lead to loss of tolerance to ox-LDL antigens (Nilsson and Hansson, 2008). Thus, the intensity of the immune response to ox-LDL may determine the progression of CVD in SLE.

\section{Apo A-1 and Anti-Apo Antibody}

Apo A-1 is the major lipid-binding protein in HDL. Elevated plasma apo A-1 can significantly repress the activation of cells and the secretion of interferon- $\gamma$ (IFN- $\gamma$ ) in apo A-1 genetically modified lupus-prone mouse models (Black et al., 2015). Fewer $\mathrm{CD} 4^{+} \mathrm{T}$ cells infiltrated the kidney, and glomerulonephritis was also improved in this model. The administration of apo A-1 analogues can relieve lupus-like manifestations in lupus-prone mouse models (Woo et al., 2010).

Anti-apo A-1 antibodies are commonly found in SLE patients, even very early in the disease course (Croca et al., 2015). The titres of anti-apo A-1 antibody are positively correlated with SLErelated auto-antibodies and the SLE disease activity index (SLEDAI) (Radwan et al., 2014; Croca et al., 2015). AntioxLDL and anti-apo B antibodies were observed in primary antiphospholipid syndrome (APS) (Zhao et al., 2001) and SLE patients (Svenungsson et al., 2001). Their levels are much higher in SLE patients with high disease activity (O'Neill et al., 2010). In addition, these antibodies cross-react with anti-cardiolipin (Delgado Alves et al., 2003), indicating a potential interaction between the immune response and lipid metabolism in SLE. Antibodies against lipid components might be novel biomarkers that indicate SLE disease activity (Hahn, 2010).

\section{Dyslipidaemia in Lupus Nephritis (LN)}

Decreased HDL and Apo B levels as well as increased LDL, TG and TC levels were observed in SLE patients with LN (Liu et al., 2014), even in the quiescent phase (Chong et al., 2011). Disease activity aggravates the abnormal lipid profile course in patients with SLE (Borba and Bonfa, 1997). Dyslipidaemia can enhance the $\mathrm{CXCR}^{+}$follicular $\mathrm{T}$ helper cell $\left(\mathrm{T}_{\mathrm{FH}}\right.$ cell) response and promote immunoglobulin $\operatorname{IgG} 2 \mathrm{c}$ production in a manner dependent on Toll-like receptor 4 (TLR4) and the cytokine IL27 in the SLE mouse model (Ryu and Chung, 2018; Ryu et al., 2018). Hyperlipidaemia could amplify complement activation and enhance renal inflammation, thus promoting nephritis, in lupus-prone mouse models (Lewis et al., 2012).

\section{FA Metabolism in SLE}

N-3 polyunsaturated fatty acids (PUFAs) and n-6 PUFAs are reduced, while their downstream products (5-HETE and leukotriene B4) are markedly elevated in serum from SLE patients (Wu et al., 2012). Free fatty acids (FFAs) are common regulators of inflammation, immunity and lipid metabolism (de Jong et al., 2014). Elevated serum FFAs are observed in SLE patients with intestinal dysbiosis, indicating a potential link to the 
gut microbiota (Rodriguez-Carrio et al., 2017). Evidence shows that both Prostaglandin D2 (PGD2) and Resolvin D1 (RvD1) can restore homeostasis in inflammatory tissues. Lower levels of RvD1 were found in SLE patients (Navarini et al., 2018). PGD2 could aggravate SLE disease by promoting basophil accumulation in the lymph nodes through interactions with the CXCL12-CXCR4 axis, and antagonize PGD2 receptors (PTGDR) can reduce lupus-like disease in induced and spontaneous mouse models (Pellefigues et al., 2018), PGD2/ PTGDR axis maybe a ready-to-use therapeutic target in SLE.

\section{Potential Treatment Based on Lipid Metabolism in SLE \\ Statins}

Treatment with statins seems to be beneficial to SLE patients, but the effects are still elusive. Aggressive treatment of dyslipidaemia reduces the risk of lupus nephritis and atherosclerosis (Lewis et al., 2012). In SLE patients, fluvastatin could regulate the lipid metabolism pathway in monocytes and exert anti-oxidative and anti-inflammatory effects (Ruiz-Limon et al., 2015). Atorvastatin can restore T cell signalling and reduce the levels of IL- 6 and IL10 (Jury et al., 2006), but its effects on SLE disease activity were controversial in a double-blind randomized clinical trial (Fatemi et al., 2014). In a 11-year follow-up cohort, statins could reduce the risk of mortality, CVD and end-stage renal disease only in SLE patients with high disease activity (Yu et al., 2015).

\section{FA Supplements}

Oral fish oil (FO) can upregulate the levels of IL-13, downregulate the levels of IL-12 and restore systemic inflammation in SLE patients (Arriens et al., 2015). N-3 FAs can upregulate adiponectin in SLE patients (Lozovoy et al., 2015). Both FO and N-3 FAs can promote macrophage uptake of apoptotic cells and decrease the levels of $\mathrm{CD} 4{ }^{+} \mathrm{T}$ infiltration in the kidney, with the latter effect leading to relief of renal disease (Itoh et al., 2007; Shirai and Suzuki, 2008). Beyond the recommended doses, DHA and EPA extended the lifespan in a dose-dependent manner, downregulated the levels of antidsDNA antibodies and the pro-inflammatory cytokines IL$1 \beta$, IL-6, and TNF- $\alpha$, and attenuated glomerulonephritis in SLE patients (Halade et al., 2013). Peripheral blood mononuclear cells (PBMCs) pre-exposed to EPA or DHA reduced the expression of IL-1 $\beta$, IL- 2 and TNF- $\alpha$ in both SLE patients and healthy controls after stimulation with methylmercury (MeHg). N-3 long-chain PUFAs can reduce the extent of the inflammatory response, and their antiinflammatory effects are more effective in PBMCs from healthy controls than in PBMCs from SLE patients (Crowe et al., 2018).

\section{LIPID METABOLISM DISORDERS IN RA}

RA is a chronic inflammatory autoimmune disease affecting $0.5-1 \%$ of the population (Symmons et al., 2002). The disorder of HDL, LDL and TC levels has been reported in the active course of RA (Choy and Sattar, 2009), and a higher prevalence of dyslipidaemia was observed in RA patients (Garcia-Gomez et al., 2009). Moreover, lipid abnormalities are associated with systemic inflammation in RA patients (Dessie et al., 2020). Based on the study of female RA patients and age-matched non-RA female controls, the relationship between lipid metabolism and skeletal muscle mass was found in RA, and it's independent of disease severity and body fat mass (Matsumoto et al., 2020).

\section{Dyslipidaemia in RA}

HDL anti-oxidant capacity is negatively correlated with RA disease activity. Oxidation rates were $56 \%$ higher in RA patients with high inflammation (Gomez Rosso et al., 2014). Pro-oxidant HDL was increased more than five times in RA patients compared to normal controls (McMahon et al., 2006). High levels of HDL were correlated with erythrocyte sedimentation rate (ESR), high sensitivity C-reactive protein (hsCRP) and Disease Activity Score in 28 joints (DAS28) (Charles-Schoeman et al., 2009). A reduction of cholesterol efflux capacity was observed in RA patients with high DAS28 scores (Charles-Schoeman et al., 2012).

The levels of serum ox-LDLs (Kim et al., 2004; Vuilleumier et al., 2010) and anti-apoA-1 IgG (Kim et al., 2004) are also associated with RA disease activity. Increased levels of ox-LDLs were found in synovial fluid (Dai et al., 2000) and synovium (Winyard et al., 1993) and were positively correlated with IMT in RA patients with CVD (Ahmed et al., 2010). In addition, antiapoA-1 IgG appears to be independent of traditional CVD risk factors and therapeutic effects. Therefore, measurement of lipid profiles and identification of inflammatory status might help us to assess the development of diseases.

Moreover, liver X receptor a (LXR $\alpha)$ mediated key lipogenic enzymes, such as fatty acid translocase (CD36/FAT), lipoprotein lipase (LPL), adipocyte fatty acid-binding protein (aP2/FABP4) and cholesterol $7 \alpha$ and $27 \alpha$ hydroxylase (CYP7A, CYP27 A), can aggravate dyslipidaemia in adjuvant-induced arthritis (Xie et al., 2021). And repress LXRa agonism enables to reverse the dyslipidaemia in RA. This study indicates a potential therapy target to develop new drugs against RA with dyslipidaemia, further mechanisms need to be revealed.

\section{FA Metabolism in RA}

Lower serum FFAs are observed in newly diagnosed RA patients (Young et al., 2013). PGE2 was increased in the synovial fluid of RA patients and altered after treatment. Compared to nonsteroidal anti-inflammatory drugs, steroids can elevate PGE2 levels (Hishinuma et al., 1999). High levels of LTB4 were also found in the SF of RA patients (Davidson et al., 1983). The LTB4 secretion capacity of neutrophils was enhanced, suggesting that it may be involved in the pathogenesis of RA (Elmgreen et al., 1987). LTB4 can also mediate the expression of IL- $1 \beta$ and TNFa in RA synovial fibroblasts (RASFs) (Xu et al., 2010) and influence the invasion and migration capacity of RASFs (Chen et al., 2010). Joint administration LTB4 contributes to bone loss by promoting osteoclast activity (Garcia et al., 1996). 15-Lipoxygenase (15LOX) mRNA was detected in type B synoviocytes of RA 
patients and participated in the production of 15-HETE, which can be promoted by IL- 4 and IL- $1 \beta$ (Liagre et al., 1999). Higher levels of pro-inflammatory cytokine IL-6 and IL-8, monocyte chemotactic 1 and growth-related oncogene a were secreted by FFAs-stimulated osteoblasts from RA patients (Frommer et al., 2019). And no association was found with Wnt signalling pathway and receptor activator of nuclear kappa B ligand (RANKL). Instead, inhibiting TLR-4 can remarkably reduce PA-induced IL-8 secretion, but no effects were found with blocking TLR-2. Thus, the FFA signalling for osteoblasts might be dependent on innate immune system and inflammation.

\section{Potential Treatments Based on Lipid Metabolism in RA \\ Anti-Rheumatic Drugs}

Dyslipidaemia can be reversed by anti-inflammatory and antirheumatic drugs in RA patients without using statins (GarciaGomez et al., 2009; Steiner and Urowitz, 2009). Glucocorticoid treatment can elevate HDL levels and reduce the risk of CVD (Hahn et al., 2007). However, the activity of cholesteryl ester transfer protein is still low in RA patients treated with glucocorticoid therapy (Ferraz-Amaro et al., 2013). Rituximab and anti-TNF therapies can increase the levels of ox-LDLs temporarily at three months and can also increase the level of Apo A-1 (Ajeganova et al., 2011). RA patients treated with methotrexate (MTX) or MTX combined with anti-TNF (Hjeltnes et al., 2013) or tocilizumab (Schultz et al., 2010) have lower levels of lipoproteins.

\section{Statins}

Statins can exert anti-inflammatory and anti-oxidative effects in normal controls (McMahon and Brahn, 2008), which can inhibit co-stimulatory factors on the surface of antigen-presenting cells and IFN $\gamma$-induced Class II major histocompatibility complex (MHC) antigens on the surface of macrophages (Kwak et al., 2000). Atorvastatin can effectively reduce the anti-inflammatory effects of HDL (Charles-Schoeman et al., 2007). Overdosage of simvastatin can relieve arthritis inflammation in RA mouse models and downregulate the expression of pro-inflammatory cytokines (Leung et al., 2003).

\section{FA Supplements}

Anti-inflammatory effects of FO were demonstrated in RA (Kremer et al., 1985), especially for reducing the secretion of IL-1 by monocytes, restoring the concentrations of CRP and normalizing the chemotaxis of neutrophils. N-3 long-chain PUFA administration decreased the degree of swelling and the duration of morning stiffness (Berbert et al., 2005). FO and arachidonic acid (AA) supplementation decreased proinflammatory factors (LTB4 and prostaglandin metabolites) and improved joint pain in RA patients ((Adam et al., 2003), (Volker et al., 2000)). In addition, daily oral EPA and DHA can help RA patients reduce their NSAID dosage without deterioration of their condition (Galarraga et al., 2008). However, no significant clinical improvement was observed for low-dosage oral EPA and DHA $(1.4 \pm 0.2 \mathrm{~g})$, and the effects may be dosage dependent (Remans et al., 2004). Meanwhile, activation of fatty acid sensing GPCR (Gpr84) or mediumchain FFAs supplementation are supposed to preventing the progression of osteoarthritis without cartilaginous side effect (Wang et al., 2020).

\section{LIPID METABOLISM DISORDERS IN SSC}

SSc is a devasting autoimmune disease that involves vascular damage and progressive fibrosis of internal organs (Denton and Khanna, 2017). Adipose tissue loss and oxidative stress contribute to fibrosis.

\section{Dyslipidaemia in SSc}

Lower levels of HDL-C and higher levels of LDL were found in SSc patients (Tsifetaki et al., 2010), and carotid artery IMTs were also significantly higher. Lipoprotein(a) is synergy with prothrombotic conditions in the pathogenesis of vascular damage in SSc (Lippi et al., 2006). The ox-LDL/ß2GPI complex is induced by oxidative stress and participates in autoimmune vascular inflammation in SSc (Lopez et al., 2005).

\section{Adipose Tissue in SSc}

Atrophied intradermal adipose tissue, first observed in 1972, is replaced by fibrosis during skin induration in SSc patients (Fleischmajer et al., 1972). In addition, downregulated adipogenic markers (Wu et al., 2009; Marangoni et al., 2015) peroxisome proliferator activated receptor- $\gamma 2$ (PPAR $\gamma 2)$, fatty acid-binding protein 4 (FABP4) and adiponectin) as well as reduced thickness and total volume of dermal white adipose tissue (dWAT) (Kasza et al., 2016) were detected in skin from scleroderma mouse models. Adipose tissue plays critical roles in the pro-oxidative/anti-oxidative system (Winsz-Szczotka et al., 2016), the latter is also identified as a major cause of vascular damage in SSc (Bruckdorfer et al., 1995; Sambo et al., 2001). Oxidative injury, such as lipid peroxidation, leads to structural and functional disorders of the erythrocyte membrane and contributes to microvascular damage (Solans et al., 2000).

\section{FAs in SSc}

Numerous studies have reported that FAs and their metabolites are involved in fibrosis. Upregulated LTB4 (Kowal-Bielecka et al., 2003; Kowal-Bielecka et al., 2005) and leukotriene E4 (LTE4) (Kowal-Bielecka et al., 2003) were found in bronchoalveolar lavage (BAL) fluid from SSc patients and were revealed to be parameters of inflammation in the lungs. LOX plays a critical role in the process of leukotriene synthesis. 5-LOX-derived leukotrienes were involved in the development of lung fibrosis in bleomycin-induced mouse models (Beller et al., 2004), and the fibrosis index was alleviated in 5-LOX knockout mice (Selman et al., 2004). Unlike the function of the leukotriene subfamily, PGE2 (Wilborn et al., 1995) and Prostaglandin I2 (PGI2) (Soberman and Christmas, 2006) are antifibrogenic, while PGF2 $\alpha$ (Oga et al., 2009) is profibrogenic. In vitro, PGI2 analogues (iloprost, treprostinil and beraprost) can affect $T_{H}$ cell differentiation programmes and promote $T_{H}$ 
17 cell responses in SSc PBMCs (Truchetet et al., 2012). Upregulated PGF2 $\alpha$ synthesis promotes the development of fibrosis in a bleomycin-induced mouse model (Kanno et al., 2013).

Murine 12/15-LOX and human 15-LOX are enzymes that regulate AA metabolism. The 12/15-LOX pathway was well studied in two types of mouse models of dermal fibrosis (tight skin model and bleomycin-induced mouse model) (Kronke et al., 2012), which revealed that 12/15-LOX-deficient mice have a higher susceptibility to dermal fibrosis than WT mice. Moreover, 12/15-LOX-deficient fibroblast cells are more responsive to TGF- $\beta 1$ stimulation. These results fully proved that $12 / 15$-LOX is a negative mediator of fibrosis.

Nitrated fatty acids (NFAs) could reverse myofibroblasts and enhance collagen uptake by alveolar macrophages in a mouse model of pulmonary fibrosis (Reddy et al., 2014). 8-Isoprostane, an oxidized lipid produced by oxidative stress, has been shown to be correlated with parameters of vascular damage and pulmonary fibrosis in SSc patients (Tsou et al., 2015). Different levels of metabolites involved in FA oxidation processes were observed in both the blood and immune cells (plasma and DCs) of SSc patients compared to healthy controls. Alternation of these metabolites increased the production of pro-inflammatory cytokines IL6 which further promote fibrosis process (Ottria et al., 2020).

\section{Potential Treatments Based on Lipid Metabolism in SSc Statins}

Vascular endothelial cells are a vital component of the vascular wall. Dysfunction of endothelial cells represents an early marker of multiple vasculopathy-like atherosclerosis and SSc. Statins could protect endothelial cells from various risk factors and enhance their function (Obama et al., 2004). Statin therapy downregulates chemokines and their receptors on endothelial cells, thus exerting an anti-inflammatory effect against vascular damage (Steffens and Mach, 2004). Endothelial-protective effects are dose- and duration-dependent in SSc (Kotyla, 2018). Statin administration leads to fibroblast apoptosis in vitro in models of fibrotic disorders (Tan et al., 1999; Rombouts et al., 2003).

\section{FA Supplements}

The beneficial antifibrotic and endothelial-protective effects of FAs (DHA, PEA and linoleic acid (LA)) were primarily explored in other fibrotic diseases (Chen et al., 2011; Bianchini et al., 2012; Kang et al., 2015). Downregulated matrix metalloproteinase-2 (MMP2), blocked mesenchymal-to-mesenchymal transition (MMT) and a reversed myofibroblast phenotype were revealed in DHA-exposed human prostate fibrocytes, thus inhibiting tumorigenesis (Bianchini et al., 2012). Lipid metabolism is largely downregulated in human kidney fibrosis samples, and deficiency of FA oxidation in tubule epithelial cells plays a critical role in metabolic reprogramming (Kang et al., 2015). Correcting lipid metabolism disorders effectively protects mice from tubulointerstitial fibrosis. FO supplementation can prevent cardiac fibrosis by activating the cyclic GMP/protein kinase $\mathrm{G}$ (cGMP/PKG) signalling pathway (Chen et al., 2011). Given that
FO administration is well tolerated and safe in clinical practice, novel therapy trials should be applied to SSc.

\section{LIPID METABOLISM DISORDERS IN IIM}

IIMs are chronic autoimmune myopathies characterized by skeletal muscle weakness and fatigue. The major subgroups of IIM are polymyositis (PM), dermatomyositis (DM), inclusion body myositis (IBM) and immune-mediated necrotic myopathy (IMNM) (Mariampillai et al., 2018).

\section{Dyslipidaemia in IIM}

Dyslipidaemia is a common disorder in untreated DM patients and indicates a high risk of atherosclerosis (Wang et al., 2013). A negative correlation between CRP and HDL-C was found in DM patients, suggesting that inflammation may contribute to changes in the serum lipid profile. Sixty-five percent of juvenile DM patients were found to have quantitative subcutaneous fat loss, and $66 \%$ of these patients had hypertriglyceridemia (Verma et al., 2006). Whether both contribute to juvenile DM remains elusive. Cholesterol, lowdensity lipoprotein receptor (LDLR), very low-density lipoprotein receptor (VLDLR) and lipoprotein receptorrelated protein (LRP) were increased in the muscle tissues of IBM patients (Jaworska-Wilczynska et al., 2002), which might be involved in the formation of vacuolated muscle fibres (VMF) by interacting with amyloid- $\beta$ precursor protein $(\mathrm{A} \beta \mathrm{PP})$. The accumulation of LDLR and VLDLR may participate in the pathogenesis of IBM or repair and necrotizing processes.

\section{FAs in IIM}

Accumulated evidence has revealed that AA metabolites (mainly leukotriene and prostaglandin subfamilies) are involved in skeletal muscle repair, proliferation and differentiation (Prisk and Huard, 2003; Sun et al., 2009). LTB4, secreted by neutrophils, macrophages, dendritic cells and mast cells, is a powerful chemokine that induces myeloid leukocytes and is a potential marker of activated $\mathrm{T}$ cell migration to inflamed muscle tissues (Page et al., 2004). The LTB4 pathway was found to be upregulated in the skeletal muscle tissues of $\mathrm{PM} / \mathrm{DM}$ patients and negatively correlated with muscle weakness and fatigue (Loell et al., 2013).

Lymphocyte inflammation plays a critical role in the pathogenesis of PM (Dalakas, 2015), and mechanistic target of rapamycin (mTOR) signalling participates in this process. mTOR interacts with inflammation and metabolism and strongly controls de novo synthesis of palmitoleic acid (PA). Thus, upregulated PA was proposed to be a novel marker of PM (Yin et al., 2017).

\section{Potential Treatments Based on Lipid Metabolism in IIM Anti-Rheumatic Drugs}

Treatment with immunosuppressive agents in adult DM/PM patients can significantly dysregulate the expression of lipid 
TABLE 1 | Dyslipidaemia in rheumatic diseases.

\begin{tabular}{|c|c|c|c|}
\hline $\begin{array}{l}\text { Rheumatic } \\
\text { diseases }\end{array}$ & Dyslipidaemia & Functions & Reference \\
\hline \multirow[t]{4}{*}{ SLE } & piHDL $\uparrow$ & Positively correlated with carotid plaque and IMTs & McMahon et al. (2006), Wu et al. (2016) \\
\hline & $\mathrm{PON}-1 \downarrow$ & Protect LDLs from oxidation & Kiss et al. (2007) \\
\hline & $\mathrm{LDL} \uparrow$ & Positively correlated with plaque inflammation & Navab et al. (2004) \\
\hline & Apo-B,TG,TC $\uparrow$ & Observed in LN patients & Hahn (2010), Liu et al. (2014) \\
\hline RA & Pro-oxidant HDL $\uparrow$ & Positively correlated with ESR, hsCRP and DAS28 & McMahon et al. (2006), Gomez Rosso et al. (2014) \\
\hline & Lipoprotein(a) $\uparrow$ & Positively correlated with vascular damage & Tsifetaki et al. (2010) \\
\hline & Ox-LDL/ $\beta 2$ GPI complex $\uparrow$ & $\begin{array}{l}\text { Positively correlated with autoimmune vascular } \\
\text { inflammation }\end{array}$ & Lippi et al. (2006) \\
\hline \multirow[t]{2}{*}{ IIM } & $\mathrm{HDL}-\mathrm{C} \downarrow$ & Negative correlated with CRP and inflammation & Mariampillai et al. (2018) \\
\hline & $\begin{array}{l}\text { Cholesterol, LDLR, } \\
\text { VLDLR, LRP } \uparrow\end{array}$ & Involved in the formation of vacuolated muscle fibres & Wang et al. (2013) \\
\hline
\end{tabular}

metabolism-related genes (Loell et al., 2016), such as upregulation of FA uptake and transport genes (fatty acid-binding protein 7 and subfamily D member 2) and lipolysis genes (lipoprotein lipase, carboxylesterase 1 and hormone-sensitive lipase) and downregulation of anti-lipolysis genes (lipid storage droplet protein), which suggests enhanced generation of free FAs and intramuscular lipid accumulation, leading to skeletal muscle dysfunction.

\section{FA Supplements}

Oral FO can improve muscle function and strength in elderly women and improve muscle weakness and fatigue in myositis patients (Rodacki et al., 2012). 5-Lipoxygenase activating protein (FLAP) is the determining leukotrienes synthesis protein (Back et al., 2007), including LTB4 synthesis (Borgeat and Naccache, 1990). However, immunosuppressive treatment of DM/PM cannot sufficiently suppress the LTB4 pathway, and FLAP inhibitors might be an ideal choice; this possibility requires further investigation.

\section{LIPID METABOLISM DISORDERS IN PSS}

Primary Sjögren's syndrome (pSS) is an autoimmune disease characterized by progressive lymphocytic infiltration into exocrine glands. pSS patients have a higher prevalence of metabolic disorders, such as dyslipidaemia and diabetes (Ramos-Casals et al., 2007; Kang and Lin, 2010). The relationship between metabolic disorders and pSS was first discovered in 1977 and described as 'pseudo-SS' (Goldman and Julian, 1977).

\section{Dyslipidaemia in pSS}

Dyslipidaemia was positively correlated with minor salivary gland morphological changes in xerostomic patients (Lukach et al., 2014). These altered lipid profiles are associated with high levels of ESR (Cruz et al., 2010), and hypercholesterolemia is negatively correlated with immunological markers (complement C3, complement C4, anti-Ro and anti-La) (Ramos-Casals et al.,
2007). Thus, lipid profiles might be valuable for evaluating disease activity.

\section{FAs in pSS}

A link between palmitic acid levels in the blood and the pathogenesis of pSS was revealed (Shikama et al., 2013). Palmitic acid is involved in the differentiation of $\mathrm{CD}^{+}$ T cells and induces IL-6 production (Rincon et al., 1997), thus promoting local inflammation and monocyte infiltration in the salivary glands (Sekiguchi et al., 2008). High levels of palmitic acid can also induce epithelial cell apoptosis in the salivary glands (Miller et al., 2005), leading to an elevated level of $a$-fodrin fragment, which is an auto-antigen in the pathogenesis of pSS (Haneji et al., 1997). In addition, a highfat diet leads to advanced inflammation in the salivary glands and an elevated titre of auto-antibodies in a mouse model of pSS (Haneji et al., 1994).

\section{Potential Treatments Based on Lipid Metabolism in pSS Anti-Rheumatic Drugs}

In pSS patients, hydroxychloroquine (HCQ) administration reverses the disorder of TG and HDL levels (Migkos et al., 2014), which are strongly correlated with the risk of atherogenesis. This implies that dyslipidaemia is a specific symptom in the pSS population, rather an independent risk factor for atherogenesis.

\section{FA Supplements}

Lipid-related molecules are beneficial for the salivary glands both in vitro and in vivo. DHA can inhibit palmitic acid-induced IL-6 and IL-8 production (Shikama et al., 2015). The RvD1 biosynthetic pathway was shown to exist in murine and human salivary gland cells (Leigh et al., 2014), and its biosynthesis-related mediators are quite different in salivary gland cells from pSS patients than in those from normal controls. RvD1 can inhibit TNF-a-mediated inflammation, increase cell polarity and enhance the barrier function of 
salivary glands (Odusanwo et al., 2012; Nelson et al., 2014). Therefore, DHA supplementation may be a novel therapy for pSS patients (Table 1).

\section{CONCLUSION}

Altered lipid profiles are common in rheumatic diseases. Dyslipidaemia, a traditional risk factor for atherosclerosis, participates in the development of rheumatic diseases. The coexistence of rheumatic diseases and atherosclerotic diseases increases the mortality of rheumatic diseases. Statin agents not only lower atherosclerotic risk but also seem to be immunomodulators of rheumatic diseases. FA metabolism also plays critical roles. How altered FAs and their metabolites regulate inflammation and exert other specific effects remains unknown. Vascular damage in autoimmune diseases is partly caused by the oxidation of FAs and their metabolites. Lipid metabolism can directly influence T cell (de Jong et al., 2014) and macrophage (Galvan-Pena and O'Neill, 2014) function. CTLA-4, ICOS molecules and lipid synthesis pathways are

\section{REFERENCES}

Adam, O., Beringer, C., Kless, T., Lemmen, C., Adam, A., Wiseman, M., et al. (2003). Anti-inflammatory effects of a low arachidonic acid diet and fish oil in patients with rheumatoid arthritis. Rheumatol. Int. 23 (1), 27-36. doi:10.1007/ s00296-002-0234-7

Ahmed, H. M., Youssef, M., and Mosaad, Y. M. (2010). Antibodies against oxidized low-density lipoprotein are associated with subclinical atherosclerosis in recentonset rheumatoid arthritis. Clin. Rheumatol. 29 (11), 1237-1243. doi:10.1007/ s10067-010-1436-0

Ajeganova, S., Fiskesund, R., de Faire, U., Hafstrom, I., and Frostegard, J. (2011). Effect of biological therapy on levels of atheroprotective antibodies against phosphorylcholine and apolipoproteins in rheumatoid arthritis - a one year study. Clin. Exp. Rheumatol. 29 (6), 942-950.

Arriens, C., Hynan, L. S., Lerman, R. H., Karp, D. R., and Mohan, C. (2015). Placebo-controlled randomized clinical trial of fish oil's impact on fatigue, quality of life, and disease activity in systemic lupus erythematosus. Nutr. J. 14, 82. doi:10.1186/s12937-015-0068-2

Aviram, M., and Rosenblat, M. (2004). Paraoxonases 1, 2, and 3, oxidative stress, and macrophage foam cell formation during atherosclerosis development. Free Radic. Biol. Med. 37 (9), 1304-1316. doi:10.1016/j.freeradbiomed.2004.06.030

Back, M., Sultan, A., Ovchinnikova, O., and Hansson, G. K. (2007). 5Lipoxygenase-activating protein: a potential link between innate and adaptive immunity in atherosclerosis and adipose tissue inflammation. Circ. Res. 100 (7), 946-949. doi:10.1161/01.RES.0000264498.60702.0d

Beller, T. C., Friend, D. S., Maekawa, A., Lam, B. K., Austen, K. F., and Kanaoka, Y. (2004). Cysteinyl leukotriene 1 receptor controls the severity of chronic pulmonary inflammation and fibrosis. Proc. Natl. Acad. Sci. United States. 101 (9), 3047-3052. doi:10.1073/pnas.0400235101

Berbert, A. A., Kondo, C. R., Almendra, C. L., Matsuo, T., and Dichi, I. (2005). Supplementation of fish oil and olive oil in patients with rheumatoid arthritis. Nutri. 21 (2), 131-136. doi:10.1016/j.nut.2004.03.023

Bianchini, F., Giannoni, E., Serni, S., Chiarugi, P., and Calorini, L. (2012). 22 : 6n-3 DHA inhibits differentiation of prostate fibroblasts into myofibroblasts and tumorigenesis. $\quad B r . \quad J . \quad N u t r . \quad 108$ (12), 2129-2137. doi:10.1017/ S0007114512000359

Black, L. L., Srivastava, R., Schoeb, T. R., Moore, R. D., Barnes, S., and Kabarowski, J. H. (2015). Cholesterol-independent suppression of lymphocyte activation, autoimmunity, and glomerulonephritis by apolipoprotein A-I in defective in raptor-deficient regulatory $\mathrm{T}$ (Treg) cells (Zeng et al., 2013).

Little is known about the interactions among lipid metabolism, immune cell function and rheumatic diseases. Immunometabolism may be vital in the development of rheumatic diseases. Given the importance of lipid profiles and metabolism, further investigations about mechanism and therapeutic strategies are urgently needed.

\section{AUTHOR CONTRIBUTIONS}

WC: Writing-Original draft preparation. QW, BZ, LZ and HZ: Reviewing-Editing.

\section{FUNDING}

This work was supported by grants from National Natural Science Foundation of China $(81771765,81701621)$, Hunan Provincial Natural Science Foundation (2019JJ40503, 2018JJ3823).

normocholesterolemic lupus-prone mice. J. Immunol. 195 (10), 4685-4698. doi:10.4049/jimmunol.1500806

Borba, E. F., and Bonfa, E. (1997). Dyslipoproteinemias in systemic lupus erythematosus: influence of disease, activity, and anticardiolipin antibodies. Lupus 6 (6), 533-539. doi:10.1177/096120339700600610

Borgeat, P., and Naccache, P. H. (1990). Biosynthesis and biological activity of leukotriene B4. Clin. Biochem. 23 (5), 459-468. doi:10.1016/0009-9120(90) 90272-v

Bruckdorfer, K. R., Hillary, J. B., Bunce, T., Vancheeswaran, R., and Black, C. M. (1995). Increased susceptibility to oxidation of low-density lipoproteins isolated from patients with systemic sclerosis. Arthritis Rheum. 38 (8), 1060-1067. doi:10.1002/art.1780380807

Charles-Schoeman, C., Khanna, D., Furst, D. E., McMahon, M., Reddy, S. T., et al. (2007). Effects of high-dose atorvastatin on antiinflammatory properties of high density lipoprotein in patients with rheumatoid arthritis: a pilot study. J. Rheumatol. 34 (7), 1459-1464.

Charles-Schoeman, C., Watanabe, J., Lee, Y. Y., Furst, D. E., Amjadi, S., Elashoff, D., et al. (2009). Abnormal function of high-density lipoprotein is associated with poor disease control and an altered protein cargo in rheumatoid arthritis. Arthritis Rheum. 60 (10), 2870-2879. doi:10.1002/art.24802

Charles-Schoeman, C., Lee, Y. Y., Grijalva, V., Amjadi, S., FitzGerald, J., Ranganath, V. K., et al. (2012). Cholesterol efflux by high density lipoproteins is impaired in patients with active rheumatoid arthritis. Ann. Rheum. Dis. 71 (7), 1157-1162. doi:10.1136/annrheumdis-2011-200493

Chen, M., Lam, B. K., Luster, A. D., Zarini, S., Murphy, R. C., Bair, A. M., et al. (2010). Joint tissues amplify inflammation and alter their invasive behavior via leukotriene B4 in experimental inflammatory arthritis. J. Immunol. 185 (9), 5503-5511. doi:10.4049/jimmunol.1001258

Chen, J., Shearer, G. C., Chen, Q., Healy, C. L., Beyer, A. J., Nareddy, V. B., et al. (2011). Omega-3 fatty acids prevent pressure overload-induced cardiac fibrosis through activation of cyclic GMP/protein kinase G signaling in cardiac fibroblasts. Circulation 123 (6), 584-593. doi:10.1161/CIRCULATIONAHA. 110.971853

Chong, Y. B., Yap, D. Y., Tang, C. S., and Chan, T. M. (2011). Dyslipidaemia in patients with lupus nephritis. Nephrology (Carlton) 16 (5), 511-517. doi:10. 1111/j.1440-1797.2011.01456.x

Choy, E., and Sattar, N. (2009). Interpreting lipid levels in the context of high-grade inflammatory states with a focus on rheumatoid arthritis: a challenge to conventional cardiovascular risk actions. Ann. Rheum. Dis. 68 (4), 460-469. doi:10.1136/ard.2008.101964 
Croca, S., Bassett, P., Chambers, S., Davari, M., Alber, K. F., Leach, O., et al. (2015). IgG anti-apolipoprotein A-1 antibodies in patients with systemic lupus erythematosus are associated with disease activity and corticosteroid therapy: an observational study. Arthritis Res. Ther. 17, 26. doi:10.1186/ s13075-015-0539-z

Crowe, W., Allsopp, P. J., Nyland, J. F., Magee, P. J., Strain, J. J., Doherty, L. C., et al. (2018). Inflammatory response following in vitro exposure to methylmercury with and without n-3 long chain polyunsaturated fatty acids in peripheral blood mononuclear cells from systemic lupus erythematosus patients compared to healthy controls. Toxicol. Vitro 52, 272-278. doi:10.1016/j.tiv.2018.05.008

Cruz, W., Fialho, S., Morato, E., Castro, G., Zimmermann, A., Ribeiro, G., et al. (2010). Is there a link between inflammation and abnormal lipoprotein profile in Sjogren's syndrome?. Jt. Bone Spine 77 (3), 229-231. doi:10.1016/j.jbspin. 2010.02.011

Dai, L., Lamb, D. J., Leake, D. S., Kus, M. L., Jones, H. W., Morris, C. J., et al. (2000). Evidence for oxidised low density lipoprotein in synovial fluid from rheumatoid arthritis patients. Free Radic. Res. 32 (6), 479-486. doi:10.1080/ 10715760000300481

Dalakas, M. C. (2015). Inflammatory muscle diseases. N. Engl. J. Med. 373 (4), 393-394. doi:10.1056/NEJMc1506827

Davidson, E. M., Rae, S. A., and Smith, M. J. (1983). Leukotriene B4, a mediator of inflammation present in synovial fluid in rheumatoid arthritis. Ann. Rheum. Dis. 42 (6), 677-679. doi:10.1136/ard.42.6.677

de Jong, A. J., Kloppenburg, M., Toes, R. E., and Ioan-Facsinay, A. (2014). Fatty acids, lipid mediators, and T-cell function. Front. Immunol. 5, 483. doi:10.3389/ fimmu.2014.00483

De Nardo, D., Labzin, L. I., Kono, H., Seki, R., Schmidt, S. V., Beyer, M., et al. (2014). High-density lipoprotein mediates anti-inflammatory reprogramming of macrophages via the transcriptional regulator ATF3. Nat. Immunol. 15 (2), 152-160. doi:10.1038/ni.2784

Delgado Alves, J., Kumar, S., and Isenberg, D. A. (2003). Cross-reactivity between anti-cardiolipin, anti-high-density lipoprotein and anti-apolipoprotein A-I IgG antibodies in patients with systemic lupus erythematosus and primary antiphospholipid syndrome. Rheumatology (Oxford) 42 (7), 893-899. doi:10. 1093/rheumatology/keg248

Denton, C. P., and Khanna, D. (2017). Systemic sclerosis. Lancet 390 (10103), 1685-1699. doi:10.1016/S0140-6736(17)30933-9

Dessie, G., Tadesse, Y., Demelash, B., and Genet, S. (2020). Assessment of serum lipid profiles and high-sensitivity C-reactive protein among patients suffering from rheumatoid arthritis at tikur anbessa specialized hospital, addis ababa, Ethiopia: a cross-sectional study. Open Access Rheumatol. 12, 223-232. doi:10. 2147/OARRR.S264466

Durrington, P. N., Mackness, B., and Mackness, M. I. (2001). Paraoxonase and atherosclerosis. Arterioscler Thromb. Vasc. Biol. 21 (4), 473-480. doi:10.1161/ 01.atv.21.4.473

Elmgreen, J., Nielsen, O. H., and Ahnfelt-Ronne, I. (1987). Enhanced capacity for release of leucotriene B4 by neutrophils in rheumatoid arthritis. Ann. Rheum. Dis. 46 (7), 501-505. doi:10.1136/ard.46.7.501

Expert, E. (2001). Panel on detection and A. Treatment of high blood cholesterol in: executive summary of the third report of the national cholesterol education program (NCEP) expert panel on detection, evaluation, and treatment of high blood cholesterol in adults (adult treatment panel III). JAMA 285 (19), 2486-2497. doi:10.1001/jama.285.19.2486

Fatemi, A., Moosavi, M., Sayedbonakdar, Z., Farajzadegan, Z., Kazemi, M., and Smiley, A. (2014). Atorvastatin effect on systemic lupus erythematosus disease activity: a double-blind randomized clinical trial. Clin. Rheumatol. 33 (9), 1273-1278. doi:10.1007/s10067-014-2654-7

Ferraz-Amaro, I., Gonzalez-Gay, M. A., Garcia-Dopico, J. A., and Diaz-Gonzalez, F. (2013). Cholesteryl ester transfer protein in patients with rheumatoid arthritis. J. Rheumatol. 40 (7), 1040-1047. doi:10.3899/jrheum.121507

Fleischmajer, R., Damiano, V., and Nedwich, A. (1972). Alteration of subcutaneous tissue in systemic scleroderma. Arch. Dermatol. 105 (1), 59-66.

Frommer, K. W., Hasseli, R., Schaffler, A., Lange, U., Rehart, S., Steinmeyer, J., et al. (2019). Free fatty acids in bone pathophysiology of rheumatic diseases. Front. Immunol. 10, 2757. doi:10.3389/fimmu.2019.02757

Gaal, K., Tarr, T., Lorincz, H., Borbas, V., Seres, I., Harangi, M., et al. (2016). Highdensity lipopoprotein antioxidant capacity, subpopulation distribution and paraoxonase-1 activity in patients with systemic lupus erythematosus. Lipids Health Dis. 15, 60. doi:10.1186/s12944-016-0229-0

Galarraga, B., Ho, M., Youssef, H. M., Hill, A., McMahon, H., Hall, C., et al. (2008). Cod liver oil (n-3 fatty acids) as an non-steroidal anti-inflammatory drug sparing agent in rheumatoid arthritis. Rheumatology (Oxford) 47 (5), 665-669. doi:10.1093/rheumatology/ken024

Galvan-Pena, S., and O’Neill, L. A. (2014). Metabolic reprograming in macrophage polarization. Front. Immunol. 5, 420. doi:10.3389/fimmu.2014.00420

Garcia, C., Boyce, B. F., Gilles, J., Dallas, M., Qiao, M., Mundy, G. R., et al. (1996). Leukotriene B4 stimulates osteoclastic bone resorption both in vitro and in vivo. J. Bone Miner Res. 11 (11), 1619-1627. doi:10.1002/jbmr.5650111105

Garcia-Gomez, C., Nolla, J. M., Valverde, J., Gomez-Gerique, J. A., Castro, M. J., and Pinto, X. (2009). Conventional lipid profile and lipoprotein(a) concentrations in treated patients with rheumatoid arthritis. J. Rheumatol. 36 (7), 1365-1370. doi:10.3899/jrheum.080928

Goldman, J. A., and Julian, E. H. (1977). Pseudo-Sjogren syndrome with hyperlipoproteinemia. JAMA 237 (15), 1582-1584.

Gomez Rosso, L., Lhomme, M., Merono, T., Sorroche, P., Catoggio, L., Soriano, E., et al. (2014). Altered lipidome and antioxidative activity of small, dense HDL in normolipidemic rheumatoid arthritis: relevance of inflammation. Atherosclerosis 237 (2), 652-660. doi:10.1016/j.atherosclerosis.2014.09.034

Hahn, B. H., Grossman, J., Chen, W., and McMahon, M. (2007). The pathogenesis of atherosclerosis in autoimmune rheumatic diseases: roles of inflammation and dyslipidemia. J. Autoimmun. 28 (2-3), 69-75. doi:10.1016/j.jaut.2007. 02.004

Hahn, B. H. (2010). Should antibodies to high-density lipoprotein cholesterol and its components be measured in all systemic lupus erythematosus patients to predict risk of atherosclerosis?. Arthritis Rheum. 62 (3), 639-642. doi:10.1002/ art.27298

Halade, G. V., Williams, P. J., Veigas, J. M., Barnes, J. L., and Fernandes, G. (2013). Concentrated fish oil (Lovaza(R)) extends lifespan and attenuates kidney disease in lupus-prone short-lived (NZBxNZW)F1 mice. Exp. Biol. Med. (Maywood) 238 (6), 610-622. doi:10.1177/1535370213489485

Haneji, N., Hamano, H., Yanagi, K., and Hayashi, Y. (1994). A new animal model for primary Sjogren's syndrome in NFS/sld mutant mice. J. Immunol. 153 (6), 2769-2777.

Haneji, N., Nakamura, T., Takio, K., Yanagi, K., Higashiyama, H., Saito, I., et al. (1997). Identification of alpha-fodrin as a candidate autoantigen in primary Sjogren's syndrome. Science 276 (5312), 604-607. doi:10.1126/science.276. 5312.604

Hansson, G. K. (2005). Inflammation, atherosclerosis, and coronary artery disease. N. Engl. J. Med. 352 (16), 1685-1695. doi:10.1056/NEJMra043430

Hishinuma, T., Nakamura, H., Sawai, T., Uzuki, M., Itabash, Y., and Mizugaki, M. (1999). Microdetermination of prostaglandin E2 in joint fluid in rheumatoid arthritis patients using gas chromatography/selected ion monitoring. Prostaglandins Other Lipid Mediat 58 (2-4), 179-186. doi:10.1016/s00906980(99)00028-3

Hjeltnes, G., Hollan, I., Forre, O., Wiik, A., Lyberg, T., Mikkelsen, K., et al. (2013). Serum levels of lipoprotein(a) and E-selectin are reduced in rheumatoid arthritis patients treated with methotrexate or methotrexate in combination with TNF-alpha-inhibitor. Clin. Exp. Rheumatol. 31 (3), 415-421.

Itoh, M., Suganami, T., Satoh, N., Tanimoto-Koyama, K., Yuan, X., Tanaka, M., et al. (2007). Increased adiponectin secretion by highly purified eicosapentaenoic acid in rodent models of obesity and human obese subjects. Arterioscler Thromb. Vasc. Biol. 27 (9), 1918-1925. doi:10.1161/ ATVBAHA.106.136853

Jaworska-Wilczynska, M., Wilczynski, G. M., Engel, W. K., Strickland, D. K., Weisgraber, K. H., and Askanas, V. (2002). Three lipoprotein receptors and cholesterol in inclusion-body myositis muscle. Neurology 58 (3), 438-445. doi:10.1212/wnl.58.3.438

Jury, E. C., Isenberg, D. A., Mauri, C., and Ehrenstein, M. R. (2006). Atorvastatin restores Lck expression and lipid raft-associated signaling in $\mathrm{T}$ cells from patients with systemic lupus erythematosus. J. Immunol. 177 (10), 7416-7422. doi:10.4049/jimmunol.177.10.7416

Kang, J. H., and Lin, H. C. (2010). Comorbidities in patients with primary Sjogren's syndrome: a registry-based case-control study. J. Rheumatol. 37 (6), 1188-1194. doi:10.3899/jrheum.090942 
Kang, H. M., Ahn, S. H., Choi, P., Ko, Y. A., Han, S. H., Chinga, F., et al. (2015). Defective fatty acid oxidation in renal tubular epithelial cells has a key role in kidney fibrosis development. Nat. Med. 21 (1), 37-46. doi:10.1038/nm.3762

Kanno, Y., Kawashita, E., Kokado, A., Okada, K., Ueshima, S., Matsuo, O., et al. (2013). Alpha2-antiplasmin regulates the development of dermal fibrosis in mice by prostaglandin $\mathrm{F}$ (2alpha) synthesis through adipose triglyceride lipase/ calcium-independent phospholipase A(2). Arthritis Rheum. 65 (2), 492-502. doi:10.1002/art.37767

Kasza, I., Hernando, D., Roldan-Alzate, A., Alexander, C. M., and Reeder, S. B. (2016). Thermogenic profiling using magnetic resonance imaging of dermal and other adipose tissues. JCI Insight 1 (13), e87146. doi:10.1172/jci.insight. 87146

Kaul, A., Gordon, C., Crow, M. K., Touma, Z., Urowitz, M. B., van Vollenhoven, R., et al. (2016). Systemic lupus erythematosus. Nat. Rev. Dis. Primers 2, 16039. doi: $10.1038 /$ nrdp.2016.39

Kim, S. H., Lee, C. K., Lee, E. Y., Park, S. Y., Cho, Y. S., Yoo, B., et al. (2004). Serum oxidized low-density lipoproteins in rheumatoid arthritis. Rheumatol. Int. 24 (4), 230-233. doi:10.1007/s00296-003-0358-4

Kim, S. Y., Yu, M., Morin, E. E., Kang, J., Kaplan, M. J., and Schwendeman, A. (2020). High-density lipoprotein in lupus: disease biomarkers and potential therapeutic strategy. Arthritis Rheumatol. 72 (1), 20-30. doi:10.1002/art. 41059

Kiss, E., Seres, I., Tarr, T., Kocsis, Z., Szegedi, G., and Paragh, G. (2007). Reduced paraoxonasel activity is a risk for atherosclerosis in patients with systemic lupus erythematosus. Ann. N. Y Acad. Sci. 1108, 83-91. doi:10.1196/annals.1422.009

Kotyla, P. J. (2018). Short course of simvastatin has no effect on markers of endothelial activation in normolipidemic patients with systemic sclerosis. J. Int. Med. Res. 46 (5), 1893-1901. doi:10.1177/0300060518762681

Kowal-Bielecka, O., Distler, O., Kowal, K., Siergiejko, Z., Chwiecko, J., Sulik, A., et al. (2003). Elevated levels of leukotriene B4 and leukotriene E4 in bronchoalveolar lavage fluid from patients with scleroderma lung disease. Arthritis Rheum. 48 (6), 1639-1646. doi:10.1002/art.11042

Kowal-Bielecka, O., Kowal, K., Distler, O., Rojewska, J., Bodzenta-Lukaszyk, A., Michel, B. A., et al. (2005). Cyclooxygenase- and lipoxygenase-derived eicosanoids in bronchoalveolar lavage fluid from patients with scleroderma lung disease: an imbalance between proinflammatory and antiinflammatory lipid mediators. Arthritis Rheum. 52 (12), 3783-3791. doi:10.1002/art.21432

Kremer, J. M., Bigauoette, J., Michalek, A. V., Timchalk, M. A., Lininger, L., Rynes, R. I., et al. (1985). Effects of manipulation of dietary fatty acids on clinical manifestations of rheumatoid arthritis. Lancet 1 (8422), 184-187. doi:10.1016/ s0140-6736(85)92024-0

Kronke, G., Reich, N., Scholtysek, C., Akhmetshina, A., Uderhardt, S., Zerr, P., et al. (2012). The 12/15-lipoxygenase pathway counteracts fibroblast activation and experimental fibrosis. Ann. Rheum. Dis. 71 (6), 1081-1087. doi:10.1136/ annrheumdis-2011-200745

Kwak, B., Mulhaupt, F., Myit, S., and Mach, F. (2000). Statins as a newly recognized type of immunomodulator. Nat. Med. 6 (12), 1399-1402. doi:10.1038/82219

Leigh, N. J., Nelson, J. W., Mellas, R. E., Aguirre, A., and Baker, O. J. (2014). Expression of resolvin D1 biosynthetic pathways in salivary epithelium. J. Dent Res. 93 (3), 300-305. doi:10.1177/0022034513519108

Leung, B. P., Sattar, N., Crilly, A., Prach, M., McCarey, D. W., Payne, H., et al. (2003). A novel anti-inflammatory role for simvastatin in inflammatory arthritis. J. Immunol. 170 (3), 1524-1530. doi:10.4049/jimmunol.170.3.1524

Lewis, M. J., Malik, T. H., Fossati-Jimack, L., Carassiti, D., Cook, H. T., Haskard, D. O., et al. (2012). Distinct roles for complement in glomerulonephritis and atherosclerosis revealed in mice with a combination of lupus and hyperlipidemia. Arthritis Rheum. 64 (8), 2707-2718. doi:10.1002/art.34451

Liagre, B., Vergne, P., Rigaud, M., and Beneytout, J. L. (1999). Arachidonate 15lipoxygenase of reticulocyte-type in human rheumatoid arthritis type B synoviocytes and modulation of its activity by proinflammatory cytokines. J. Rheumatol. 26 (5), 1044-1051.

Lippi, G., Caramaschi, P., Montagnana, M., Salvagno, G. L., Volpe, A., and Guidi, G. (2006). Lipoprotein[a] and the lipid profile in patients with systemic sclerosis. Clin. Chim. Acta 364 (1-2), 345-348. doi:10.1016/j.cca.2005.07.015

Liu, L., Zhang, T., Ye, Y., Zhang, S., and Chen, L. (2014). [Analysis of traditional cardiovascular risk factors in patients with systemic lupus erythematosus]. Zhonghua Xin Xue Guan Bing Za Zhi 42 (9), 753-758.
Loell, I., Alemo Munters, L., Pandya, J., Zong, M., Alexanderson, H., Fasth, A. E., et al. (2013). Activated LTB4 pathway in muscle tissue of patients with polymyositis or dermatomyositis. Ann. Rheum. Dis. 72 (2), 293-299. doi:10. 1136/annrheumdis-2012-201294

Loell, I., Raouf, J., Chen, Y. W., Shi, R., Nennesmo, I., Alexanderson, H., et al. (2016). Effects on muscle tissue remodeling and lipid metabolism in muscle tissue from adult patients with polymyositis or dermatomyositis treated with immunosuppressive agents. Arthritis Res. Ther. 18 (1), 136. doi:10.1186/ s13075-016-1033-y

Lopez, L. R., Simpson, D. F., Hurley, B. L., and Matsuura, E. (2005). OxLDL/ beta2GPI complexes and autoantibodies in patients with systemic lupus erythematosus, systemic sclerosis, and antiphospholipid syndrome: pathogenic implications for vascular involvement. Ann. N. Y Acad. Sci. 1051, 313-322. doi:10.1196/annals.1361.073

Lozovoy, M. A., Simao, A. N., Morimoto, H. K., Scavuzzi, B. M., Iriyoda, T. V., Reiche, E. M., et al. (2015). Fish oil N-3 fatty acids increase adiponectin and decrease leptin levels in patients with systemic lupus erythematosus. Mar. Drugs 13 (2), 1071-1083. doi:10.3390/md13021071

Lukach, L., Maly, A., Zini, A., and Aframian, D. J. (2014). Morphometrical study of minor salivary gland in xerostomic patients with altered lipid metabolism. Oral Dis. 20 (7), 714-719. doi:10.1111/odi.12195

Mackness, M. I., Arrol, S., and Durrington, P. N. (1991). Paraoxonase prevents accumulation of lipoperoxides in low-density lipoprotein. FEBS Lett. 286 (1-2), 152-154. doi:10.1016/0014-5793(91)80962-3

Manzi, S., Meilahn, E. N., Rairie, J. E., Conte, C. G., Medsger, T. A., JansenMcWilliams, L., et al. (1997). Age-specific incidence rates of myocardial infarction and angina in women with systemic lupus erythematosus: comparison with the framingham study. Am. J. Epidemiol. 145 (5), 408-415. doi:10.1093/oxfordjournals.aje.a009122

Manzi, S., Selzer, F., Sutton-Tyrrell, K., Fitzgerald, S. G., Rairie, J. E, Tracy, R. P., et al. (1999). Prevalence and risk factors of carotid plaque in women with systemic lupus erythematosus. Arthritis Rheum. 42 (1), 51-60. doi:10.1002/ 1529-0131(199901)42

Marangoni, R. G., Korman, B. D., Wei, J., Wood, T. A., Graham, L. V., Whitfield, M. L., et al. (2015). Myofibroblasts in murine cutaneous fibrosis originate from adiponectin-positive intradermal progenitors. Arthritis Rheumatol. 67 (4), 1062-1073. doi:10.1002/art.38990

Mariampillai, K., Granger, B., Amelin, D., Guiguet, M., Hachulla, E., Maurier, F., et al. (2018). Development of a new classification system for idiopathic inflammatory myopathies based on clinical manifestations and myositisspecific autoantibodies. JAMA Neurol. 75 (12), 1528-1537. doi:10.1001/ jamaneurol.2018.2598

Matsumoto, Y., Sugioka, Y., Tada, M., Okano, T., Mamoto, K., Inui, K., et al. (2020). Change in skeletal muscle mass is associated with lipid profiles in female rheumatoid arthritis patients -TOMORROW study. Clin. Nutr. doi:10.1016/j. clnu.2020.12.028

McMahon, M., and Brahn, E. (2008). Inflammatory lipids as a target for therapy in the rheumatic diseases. Expert Opin. Investig. Drugs 17 (8), 1213-1224. doi:10. $1517 / 13543784.17 .8 .1213$

McMahon, M., Grossman, J., FitzGerald, J., Dahlin-Lee, E., Wallace, D. J., Thong, B. Y., et al. (2006). Proinflammatory high-density lipoprotein as a biomarker for atherosclerosis in patients with systemic lupus erythematosus and rheumatoid arthritis. Arthritis Rheum. 54 (8), 2541-2549. doi:10.1002/art.21976

McMahon, M., Skaggs, B. J., Grossman, J. M., Sahakian, L., Fitzgerald, J., Wong, W. K., et al. (2014). A panel of biomarkers is associated with increased risk of the presence and progression of atherosclerosis in women with systemic lupus erythematosus. Arthritis Rheumatol. 66 (1), 130-139. doi:10.1002/art.38204

Migkos, M. P., Markatseli, T. E., Iliou, C., Voulgari, P. V., and Drosos, A. A. (2014). Effect of hydroxychloroquine on the lipid profile of patients with Sjogren syndrome. J. Rheumatol. 41 (5), 902-908. doi:10.3899/jrheum.131156

Miller, T. A., LeBrasseur, N. K., Cote, G. M., Trucillo, M. P., Pimentel, D. R., Ido, Y., et al. (2005). Oleate prevents palmitate-induced cytotoxic stress in cardiac myocytes. Biochem. Biophys. Res. Commun. 336 (1), 309-315. doi:10.1016/j.bbrc.2005.08.088

Narshi, C. B., Giles, I. P., and Rahman, A. (2011). The endothelium: an interface between autoimmunity and atherosclerosis in systemic lupus erythematosus? Lupus 20 (1), 5-13. doi:10.1177/0961203310382429

Navab, M., Ananthramaiah, G. M., Reddy, S. T., Van Lenten, B. J., Ansell, B. J., Fonarow, G. C., et al. (2004). The oxidation hypothesis of atherogenesis: the role 
of oxidized phospholipids and HDL. J. Lipid Res. 45 (6), 993-1007. doi:10.1194/ jlr.R400001-JLR200

Navarini, L., Bisogno, T., Margiotta, D. P. E., Piccoli, A., Angeletti, S., Laudisio, A., et al. (2018). Role of the specialized proresolving mediator resolvin D1 in systemic lupus erythematosus: preliminary results. J. Immunol. Res. 2018, 5264195. doi:10.1155/2018/5264195

Nelson, J. W., Leigh, N. J., Mellas, R. E., McCall, A. D., Aguirre, A., and Baker, O. J. (2014). ALX/FPR2 receptor for RvD1 is expressed and functional in salivary glands. Am. J. Physiol. Cell Physiol 306 (2), C178-C185. doi:10.1152/ajpcell. 00284.2013

Nilsson, J., and Hansson, G. K. (2008). Autoimmunity in atherosclerosis: a protective response losing control?. J. Intern. Med. 263 (5), 464-478. doi:10. $1111 /$ j.1365-2796.2008.01945.x

Obama, R., Ishida, H., Takizawa, S., Tsuji, C., Nakazawa, H., and Shinohara, Y. (2004). Direct inhibition by a statin of TNFalpha-induced leukocyte recruitment in rat pial venules - in vivo confocal microscopic study. Pathophysiology 11 (2), 121-128. doi:10.1016/j.pathophys.2004.07.001

Odusanwo, O., Chinthamani, S., McCall, A., Duffey, M. E., and Baker, O. J. (2012). Resolvin D1 prevents TNF-alpha-mediated disruption of salivary epithelial formation. Am. J. Physiol. Cell Physiol 302 (9), C1331-C1345. doi:10.1152/ ajpcell.00207.2011

Oga, T., Matsuoka, T., Yao, C., Nonomura, K., Kitaoka, S., Sakata, D., et al. (2009). Prostaglandin $\mathrm{F}(2 \mathrm{alpha})$ receptor signaling facilitates bleomycin-induced pulmonary fibrosis independently of transforming growth factor-beta. Nat. Med. 15 (12), 1426-1430. doi:10.1038/nm.2066

O’Neill, S. G., Giles, I., Lambrianides, A., Manson, J., D'Cruz, D., Schrieber, L., et al. (2010). Antibodies to apolipoprotein A-I, high-density lipoprotein, and C-reactive protein are associated with disease activity in patients with systemic lupus erythematosus. Arthritis Rheum. 62 (3), 845-854. doi:10. 1002/art.27286

Ottria, A., Hoekstra, A. T., Zimmermann, M., van der Kroef, M., Vazirpanah, N., Cossu, M., et al. (2020). Fatty acid and carnitine metabolism are dysregulated in systemic sclerosis patients. Front. Immunol. 11, 822. doi:10.3389/fimmu.2020. 00822

Page, G., Chevrel, G., and Miossec, P. (2004). Anatomic localization of immature and mature dendritic cell subsets in dermatomyositis and polymyositis: interaction with chemokines and Th1 cytokine-producing cells. Arthritis Rheum. 50 (1), 199-208. doi: doi:10.1002/art.11428

Park, S. H., Park, J. H., Kang, J. S., and Kang, Y. H. (2003). Involvement of transcription factors in plasma HDL protection against TNF-alpha-induced vascular cell adhesion molecule-1 expression. Int. J. Biochem. Cell Biol. 35. (2), 168-182. doi:10.1016/s1357-2725(02)00173-5

Pellefigues, C., Dema, B., Lamri, Y., Saidoune, F., Chavarot, N., Loheac, C., et al. (2018). Prostaglandin D2 amplifies lupus disease through basophil accumulation in lymphoid organs. Nat. Commun. 9 (1), 725. doi:10.1038/ s41467-018-03129-8

Peradze, N., Farr, O. M., and Mantzoros, C. S. (2019). Research developments in metabolism 2018. Metabolism 91, 70-79. doi:10.1016/j.metabol.2018.11.011

Prisk, V., and Huard, J. (2003). Muscle injuries and repair: the role of prostaglandins and inflammation. Histol. Histopathol. 18 (4), 1243-1256. doi:10.14670/HH-18.1243

Radwan, M. M., El-Lebedy, D., Fouda, R., and Elsorougy, E. (2014). Antiapolipoprotein A-1 antibodies and carotid intima-media thickness in Egyptian women with systemic lupus erythematosus. Clin. Rheumatol. 33 (4), 493-498. doi:10.1007/s10067-013-2399-8

Ramos-Casals, M., Brito-Zeron, P., Siso, A., Vargas, A., Ros, E., Bove, A., et al. (2007). High prevalence of serum metabolic alterations in primary Sjogren's syndrome: influence on clinical and immunological expression. J. Rheumatol. 34 (4), 754-761.

Reddy, A. T., Lakshmi, S. P., Zhang, Y., and Reddy, R. C. (2014). Nitrated fatty acids reverse pulmonary fibrosis by dedifferentiating myofibroblasts and promoting collagen uptake by alveolar macrophages. FASEB J. 28 (12), 5299-5310. doi:10. 1096/fj.14-256263

Remans, P. H., Sont, J. K., Wagenaar, L. W., Wouters-Wesseling, W., Zuijderduin, W. M., Jongma, A., et al. (2004). Nutrient supplementation with polyunsaturated fatty acids and micronutrients in rheumatoid arthritis: clinical and biochemical effects. Eur. J. Clin. Nutr. 58 (6), 839-845. doi:10. 1038/sj.ejcn.1601883
Rhoads, J. P., Major, A. S., and Rathmell, J. C. (2017). Fine tuning of immunometabolism for the treatment of rheumatic diseases. Nat. Rev. Rheumatol. 13 (5), 313-320. doi:10.1038/nrrheum.2017.54

Rincon, M., Anguita, J., Nakamura, T., Fikrig, E., and Flavell, R. A. (1997). Interleukin (IL)-6 directs the differentiation of IL-4-producing CD4+ T cells. J. Exp. Med. 185 (3), 461-469. doi:10.1084/jem.185.3.461

Rodacki, C. L., Rodacki, A. L., Pereira, G., Naliwaiko, K., Coelho, I., Pequito, D., et al. (2012). Fish-oil supplementation enhances the effects of strength training in elderly women. Am. J. Clin. Nutr. 95 (2), 428-436. doi:10.3945/ajcn.111. 021915

Rodriguez-Carrio, J., Lopez, P., Sanchez, B., Gonzalez, S., Gueimonde, M., Margolles, A., et al. (2017). Intestinal dysbiosis is associated with altered short-chain fatty acids and serum-free fatty acids in systemic lupus erythematosus. Front. Immunol. 8, 23. doi:10.3389/fimmu.2017.00023

Rombouts, K., Kisanga, E., Hellemans, K., Wielant, A., Schuppan, D., and Geerts, A. (2003). Effect of HMG-CoA reductase inhibitors on proliferation and protein synthesis by rat hepatic stellate cells. J. Hepatol. 38 (5), 564-572. doi:10.1016/s0168-8278(03)00051-5

Ruiz-Limon, P., Barbarroja, N., Perez-Sanchez, C., Aguirre, M. A., Bertolaccini, M. L., Khamashta, M. A., et al. (2015). Atherosclerosis and cardiovascular disease in systemic lupus erythematosus: effects of in vivo statin treatment. Ann. Rheum. Dis. 74 (7), 1450-1458. doi:10.1136/annrheumdis-2013-204351

Ryu, H., and Chung, Y. (2018). Dyslipidemia promotes germinal center reactions via IL-27. BMB Rep. 51 (8), 371-372. doi:10.5483/BMBRep.2018.51.8.171

Ryu, H., Lim, H., Choi, G., Park, Y. J., Cho, M., Na, H., et al. (2018). Atherogenic dyslipidemia promotes autoimmune follicular helper $\mathrm{T}$ cell responses via IL-27. Nat. Immunol. 19 (6), 583-593. doi:10.1038/s41590-018-0102-6

Saemann, M. D., Poglitsch, M., Kopecky, C., Haidinger, M., Horl, W. H., and Weichhart, T. (2010). The versatility of HDL: a crucial anti-inflammatory regulator. Eur. J. Clin. Invest. 40 (12), 1131-1143. doi:10.1111/j.1365-2362. 2010.02361.x

Sambo, P., Baroni, S. S., Luchetti, M., Paroncini, P., Dusi, S., Orlandini, G., et al. (2001). Oxidative stress in scleroderma: maintenance of scleroderma fibroblast phenotype by the constitutive up-regulation of reactive oxygen species generation through the NADPH oxidase complex pathway. Arthritis Rheum. 44 (11), 2653-2664. doi:10.1002/1529-0131(200111)44:11<2653::aid-art445>3. $0 . \operatorname{co} ; 2-1$

Schultz, O., Oberhauser, F., Saech, J., Rubbert-Roth, A., Hahn, M., Krone, W., et al. (2010). Effects of inhibition of interleukin-6 signalling on insulin sensitivity and lipoprotein (a) levels in human subjects with rheumatoid diseases. PLoS One 5 (12), e14328. doi:10.1371/journal.pone.0014328

Sekiguchi, M., Iwasaki, T., Kitano, M., Kuno, H., Hashimoto, N., Kawahito, Y., et al. (2008). Role of sphingosine 1-phosphate in the pathogenesis of Sjogren's syndrome. J. Immunol. 180 (3), 1921-1928. doi:10.4049/jimmunol.180.3.1921

Selman, M., Thannickal, V. J., Pardo, A., Zisman, D. A., Martinez, F. J., and Lynch, J. P. (2004). Idiopathic pulmonary fibrosis: pathogenesis and therapeutic approaches. Drugs 64 (4), 405-430. doi:10.2165/00003495-200464040-00005

Shikama, Y., Ishimaru, N., Kudo, Y., Bando, Y., Aki, N., Hayashi, Y., et al. (2013). Effects of free fatty acids on human salivary gland epithelial cells. J. Dent Res. 92 (6), 540-546. doi:10.1177/0022034513487378

Shikama, Y., Kudo, Y., Ishimaru, N., and Funaki, M. (2015). Possible involvement of palmitate in pathogenesis of periodontitis. J. Cell Physiol 230 (12), 2981-2989. doi:10.1002/jcp.25029

Shirai, N., and Suzuki, H. (2008). Effects of simultaneous intakes of fish oil and green tea extracts on plasma, glucose, insulin, C-peptide, and adiponectin and on liver lipid concentrations in mice fed low- and high-fat diets. Ann. Nutr. Metab. 52 (3), 241-249. doi:10.1159/000140516

Smith, C. K., Seto, N. L., Vivekanandan-Giri, A., Yuan, W., Playford, M. P., Manna, Z., et al. (2017). Lupus high-density lipoprotein induces proinflammatory responses in macrophages by binding lectin-like oxidised low-density lipoprotein receptor 1 and failing to promote activating transcription factor 3 activity. Ann. Rheum. Dis. 76 (3), 602-611. doi:10.1136/annrheumdis-2016209683

Soberman, R. J., and Christmas, P. (2006). Revisiting prostacyclin: new directions in pulmonary fibrosis and inflammation. Am. J. Physiol. Lung Cell Mol Physiol. 291 (2), L142-L143. doi:10.1152/ajplung.00102.2006

Soep, J. B., Mietus-Snyder, M., Malloy, M. J., Witztum, J. L., and von Scheven, E. (2004). Assessment of atherosclerotic risk factors and endothelial function in 
children and young adults with pediatric-onset systemic lupus erythematosus. Arthritis Rheum. 51 (3), 451-457. doi:10.1002/art.20392

Solans, R., Motta, C., Sola, R., Ville, A. E. L., Lima, J., Simeon, P., et al. (2000). Abnormalities of erythrocyte membrane fluidity, lipid composition, and lipid peroxidation in systemic sclerosis: evidence of free radical-mediated injury. Arthritis Rheum. 43 (4), 894-900. doi:10.1002/1529-0131(200004)43

Steffens, S., and Mach, F. (2004). Anti-inflammatory properties of statins. Semin. Vasc. Med. 4 (4), 417-422. doi:10.1055/s-2004-869599

Steiner, G., and Urowitz, M. B. (2009). Lipid profiles in patients with rheumatoid arthritis: mechanisms and the impact of treatment. Semin. Arthritis Rheum. 38 (5), 372-381. doi:10.1016/j.semarthrit.2008.01.015

Sun, R., Ba, X., Cui, L., Xue, Y., and Zeng, X. (2009). Leukotriene B4 regulates proliferation and differentiation of cultured rat myoblasts via the BLT1 pathway. Mol. Cells 27 (4), 403-408. doi:10.1007/s10059-009-0053-8

Svenungsson, E., Jensen-Urstad, K., Heimburger, M., Silveira, A., Hamsten, A., de Faire, U., et al. (2001). Risk factors for cardiovascular disease in systemic lupus erythematosus. Circulation 104 (16), 1887-1893. doi:10.1161/hc4101.097518

Symmons, D., Turner, G., Webb, R., Asten, P., Barrett, E., Lunt, M., et al. (2002). The prevalence of rheumatoid arthritis in the United Kingdom: new estimates for a new century. Rheumatology (Oxford) 41 (7), 793-800. doi:10.1093/ rheumatology/41.7.793

Tan, A., Levrey, H., Dahm, C., Polunovsky, V. A., Rubins, J., and Bitterman, P. B. (1999). Lovastatin induces fibroblast apoptosis in vitro and in vivo. A possible therapy for fibroproliferative disorders. Am. J. Respir. Crit. Care Med. 159 (1), 220-227. doi:10.1164/ajrccm.159.1.9802104

Truchetet, M. E., Allanore, Y., Montanari, E., Chizzolini, C., and Brembilla, N. C. (2012). Prostaglandin I(2) analogues enhance already exuberant Th17 cell responses in systemic sclerosis. Ann. Rheum. Dis. 71 (12), 2044-2050. doi:10.1136/annrheumdis-2012-201400

Tselios, K., Koumaras, C., Gladman, D. D., and Urowitz, M. B. (2016). Dyslipidemia in systemic lupus erythematosus: just another comorbidity? Semin. Arthritis Rheum. 45 (5), 604-610. doi:10.1016/j.semarthrit.2015.10.010

Tsifetaki, N., Georgiadis, A. N., Alamanos, Y., Fanis, S., Argyropoulou, M. I., and Drosos, A. A. (2010). Subclinical atherosclerosis in scleroderma patients. Scand. J. Rheumatol. 39 (4), 326-329. doi:10.3109/03009741003605648

Tsou, P. S., Amin, M. A., Campbell, P. L., Zakhem, G., Balogh, B., Edhayan, G., et al. (2015). Activation of the thromboxane A2 receptor by 8-isoprostane inhibits the pro-angiogenic effect of vascular endothelial growth factor in scleroderma. J. Invest. Dermatol. 135 (12), 3153-3162. doi:10.1038/jid.2015.323

Urowitz, M. B., Gladman, D., Ibanez, D., Fortin, P., Sanchez-Guerrero, J., Bae, S., et al. (2007). Clinical manifestations and coronary artery disease risk factors at diagnosis of systemic lupus erythematosus: data from an international inception cohort. Lupus 16 (9), 731-735. doi:10.1177/0961203307081113

Verma, S., Singh, S., Bhalla, A. K., and Khullar, M. (2006). Study of subcutaneous fat in children with juvenile dermatomyositis. Arthritis Rheum. 55 (4), 564-568. doi:10.1002/art.22108

Volker, D., Fitzgerald, P., Major, G., and Garg, M. (2000). Efficacy of fish oil concentrate in the treatment of rheumatoid arthritis. J. Rheumatol. 27 (10), 2343-2346.

Vuilleumier, N., Bratt, J., Alizadeh, R., Jogestrand, T., Hafstrom, I., and Frostegard, J. (2010). Anti-apoA-1 IgG and oxidized LDL are raised in rheumatoid arthritis (RA): potential associations with cardiovascular disease and RA disease activity. Scand. J. Rheumatol. 39 (6), 447-453. doi:10.3109/03009741003742755

Wang, H., Tang, J., Chen, X., Li, F., and Luo, J. (2013). Lipid profiles in untreated patients with dermatomyositis. J. Eur. Acad. Dermatol. Venereol. 27 (2), 175-179. doi:10.1111/j.1468-3083.2011.04437.x

Wang, F., Ma, L., Ding, Y., He, L., Chang, M., Shan, Y., et al. (2020). Fatty acid sensing GPCR (GPR84) signaling safeguards cartilage homeostasis and protects against osteoarthritis. Pharmacol. Res. 164, 105406. doi:10.1016/j.phrs.2020. 105406

Wigren, M., Nilsson, J., and Kaplan, M. J. (2015). Pathogenic immunity in systemic lupus erythematosus and atherosclerosis: common mechanisms and possible targets for intervention. J. Intern. Med. 278 (5), 494-506. doi:10.1111/joim. 12357

Wilborn, J., Crofford, L. J., Burdick, M. D., Kunkel, S. L., Strieter, R. M., and PetersGolden, M. (1995). Cultured lung fibroblasts isolated from patients with idiopathic pulmonary fibrosis have a diminished capacity to synthesize prostaglandin E2 and to express cyclooxygenase-2. J. Clin. Invest. 95 (4), 1861-1868. doi:10.1172/JCI117866

Winsz-Szczotka, K., Kuznik-Trocha, K., Komosinska-Vassev, K., Kucharz, E., Kotulska, A., and Olczyk, K. (2016). Relationship between adiponectin, leptin, IGF-1 and total lipid peroxides plasma concentrations in patients with systemic sclerosis: possible role in disease development. Int. J. Rheum. Dis. 19 (7), 706-714. doi:10.1111/1756-185X.12332

Winyard, P. G., Tatzber, F., Esterbauer, H., Kus, M. L., Blake, D. R., and Morris, C. J. (1993). Presence of foam cells containing oxidised low density lipoprotein in the synovial membrane from patients with rheumatoid arthritis. Ann. Rheum. Dis. 52 (9), 677-680. doi:10.1136/ard.52.9.677

Woo, J. M., Lin, Z., Navab, M., Van Dyck, C., Trejo-Lopez, Y., Woo, K. M., et al. (2010). Treatment with apolipoprotein A-1 mimetic peptide reduces lupus-like manifestations in a murine lupus model of accelerated atherosclerosis. Arthritis Res. Ther. 12 (3), R93. doi:10.1186/ar3020

Wu, M., Melichian, D. S., Chang, E., Warner-Blankenship, M., Ghosh, A. K., and Varga, J. (2009). Rosiglitazone abrogates bleomycin-induced scleroderma and blocks profibrotic responses through peroxisome proliferator-activated receptorgamma. Am. J. Pathol. 174 (2), 519-533. doi:10.2353/ajpath.2009.080574

Wu, T., Xie, C., Han, J., Ye, Y., Weiel, J., Li, Q., et al. (2012). Metabolic disturbances associated with systemic lupus erythematosus. PLoS One 7 (6), e37210. doi:10. 1371/journal.pone.0037210

Wu, G. C., Liu, H. R., Leng, R. X., Li, X. P., Li, X. M., Pan, H. F., et al. (2016). Subclinical atherosclerosis in patients with systemic lupus erythematosus: a systemic review and meta-analysis. Autoimmun. Rev. 15 (1), 22-37. doi:10. 1016/j.autrev.2015.10.002

Xie, Y., Feng, S. L., Mai, C. T., Zheng, Y. F., Wang, H., Liu, Z. Q., et al. (2021). Suppression of up-regulated LXRalpha by silybin ameliorates experimental rheumatoid arthritis and abnormal lipid metabolism. Phytomedicine 80, 153339. doi:10.1016/j.phymed.2020.153339

Xu, S., Lu, H., Lin, J., Chen, Z., and Jiang, D. (2010). Regulation of TNFalpha and ILlbeta in rheumatoid arthritis synovial fibroblasts by leukotriene B4. Rheumatol. Int. 30 (9), 1183-1189. doi:10.1007/s00296-009-1125-y

Yin, G., Wang, Y., Cen, X. M., Yang, Y., Yang, M., and Xie, Q. B. (2017). Identification of palmitoleic acid controlled by mTOR signaling as a biomarker of polymyositis. J. Immunol. Res. 2017, 3262384. doi:10.1155/ $2017 / 3262384$

Young, S. P., Kapoor, S. R., Viant, M. R., Byrne, J. J., Filer, A., Buckley, C. D., et al. (2013). The impact of inflammation on metabolomic profiles in patients with arthritis. Arthritis Rheum. 65 (8), 2015-2023. doi:10.1002/art.38021

Yu, H. H., Chen, P. C., Yang, Y. H., Wang, L. C., Lee, J. H., Lin, Y. T., et al. (2015). Statin reduces mortality and morbidity in systemic lupus erythematosus patients with hyperlipidemia: a nationwide population-based cohort study. Atherosclerosis 243 (1), 11-18. doi:10.1016/j.atherosclerosis.2015.08.030

Yuan, J., Li, L. I., Wang, Z., Song, W., and Zhang, Z. (2016). Dyslipidemia in patients with systemic lupus erythematosus: association with disease activity and B-type natriuretic peptide levels. Biomed. Rep. 4 (1), 68-72. doi:10.3892/br. 2015.544

Zeng, H., Yang, K., Cloer, C., Neale, G., Vogel, P., and Chi, H. (2013). mTORC1 couples immune signals and metabolic programming to establish $\mathrm{T}(\mathrm{reg})$-cell function. Nature 499 (7459), 485-490. doi:10.1038/nature12297

Zhao, D., Ogawa, H., Wang, X., Cameron, G. S., Baty, D. E., Dlott, J. S., et al. (2001). Oxidized low-density lipoprotein and autoimmune antibodies in patients with antiphospholipid syndrome with a history of thrombosis. Am. J. Clin. Pathol. 116 (5), 760-767. doi:10.1309/1RYQ-Q2AJ-CKF7-YCDE

Conflict of Interest: The authors declare that the research was conducted in the absence of any commercial or financial relationships that could be construed as a potential conflict of interest.

Copyright $\odot 2021$ Chen, Wang, Zhou, Zhang and Zhu. This is an open-access article distributed under the terms of the Creative Commons Attribution License (CC BY). The use, distribution or reproduction in other forums is permitted, provided the original author(s) and the copyright owner(s) are credited and that the original publication in this journal is cited, in accordance with accepted academic practice. No use, distribution or reproduction is permitted which does not comply with these terms. 


\section{GLOSSARY}

ATF-3 activating transcription factor 3

A $\beta$ PP amyloid- $\beta$ precursor protein

BAL bronchoalveolar lavage

cGMP/PKG cyclic GMP/protein kinase G

CRP C-reactive protein

CVD cardiovascular disease

DAS28 disease Activity Score in 28 joints

DM dermatomyositis

dWAT dermal white adipose tissue

ESR erythrocyte sedimentation rate

FA fatty acid

FABP4 fatty acid-binding protein 4

FAT fatty acid translocase

FFA free fatty acids

FO fish oil

HCQ hydroxychloroquine

HDL high-density lipoprotein;

hsCRP high sensitivity C-reactive protein

IBM inclusion body myositis

IFN- $\boldsymbol{\gamma}$ interferon- $\boldsymbol{\gamma}$

IIM idiopathic inflammatory myopathy

IMNM immune-mediated necrotic myopathy

IMT intima-media thickness

LDL low-density lipoprotein

LDLR low-density lipoprotein receptor

LN lupus nephritis

LPL lipoprotein lipase

LRP lipoprotein receptor-related protein

LTB4 leukotriene B4

LTE4 leukotriene E4
LXRa liver X receptor $\alpha$

MHC Class II major histocompatibility complex

MMP2 matrix metalloproteinase-2

MMT mesenchymal-to-mesenchymal transition

mTOR mechanistic target of rapamycin

MTX methotrexate

oX-LDL oxidized LDL

PBMCs peripheral blood mononuclear cells

PGD2 Prostaglandin D2

PGE2 Prostaglandin E2

PGI2 Prostaglandin I2

pi-HDL Pro-inflammatory HDL

PM polymyositis

PON-1 Paraoxonase-I

PPAR $\boldsymbol{\gamma} 2$ peroxisome proliferator activated receptor $-\gamma 2$

PPP the pentose phosphate pathway

pSS Sjögren's syndrome

PUFAs polyunsaturated fatty acids

RA rheumatoid arthritis

RANKL receptor activator of nuclear kappa B ligand

RASF RA synovial fibroblasts

RvD1 Resolvin D1

SLE systemic lupus erythematous

SLEDAI SLE disease activity index

SSc systemic sclerosis

TC total cholesterol

TCA the tricarboxylic acid

TG triglyceride

TLR Toll-like receptor

VLDLR very low-density lipoprotein receptor

VMF vacuolated muscle 